\title{
İlköğretim Matematik Eğitiminde Velinin Ev Ödevine Katılımı Tartışması1
}

DOI: $10.26466 /$ opus.658582

\author{
* \\ Fatma Erdoğan* \\ * Dr. Öğr. Üyesi, Frrat Üniversitesi, Eğitim Fakültesi, Elazığ/Türkiye \\ E-Posta: f.erdogan@firat.edu.tr \\ ORCID: 0000-0002-4498-8634 \\ Öz
}

Ev ödevi, öğrenme sürecine veli katılımını sağlayan doğal bir bağlantı yoludur. Ayrıca, matematik ödevlerine veli katılımı uluslararası alan yazında gündemde olan konulardan biridir. Bu çalışmada, öncelikle velinin ödev katılımı alan yazın tabanlı incelenmiş ve velinin ödev katılımına ilişkin teorik çerçeveden bahsedilmiştir. Sonrasında ise velinin matematik ödevine katılımıyla ilgili Türkiye'de ve dünyada yapllan çalışmalar irdelenmiştir. Bu inceleme sonucunda elde edilen sonuçlar araştırmacının önerileri ile desteklenerek sunulmuştur. Bu doğrultuda çalışmanın amacl, son yıllarda matematik eğitiminde sıklıkla vurgulanan velinin ödeve katılımını alan yazın tabanlı inceleyerek eleştirel bir bakış açısı să̆lamaktır. Dolayısıyla, bu çalışma matematik eğitiminde alana özgü bir yapıda kurgulanacak olan velinin matematik ödevine katılımı çalışmalarına ışık tutabilir. Alan yazında, velinin ödeve katılımının çok boyutlu bir yapıda olduğu görülmüştür. Velilerin ödeve katılımını ele alan araştırmaların çoğu öz-belirleme kuramını temel almaktadır. Bu teoriye göre veli katılımının veli kontrolü ve veli desteği olarak iki farklı türü vardır. İncelenen çalışma sonuçları velinin matematik ödevine katılımının öğrencilerin eğitimsel çıktılar üzerindeki etkileriyle ilgili karışık sonuçlar ortaya koymaktadır. Ayrıca, Türkiye'de velinin matematik ödevine katılımını ele alan çalışmaların oldukça sınırlı olduğu görülmüştür. Yapılacak çalışmalarda velinin matematik ödevine katılım yapısının araştırılması, hangi katılım türünün öğrenciler açısından daha iyi sonuçlar doğuracă̆ı üzerine odaklanılması önerilmektedir.

Anahtar Kelimeler: Matematik, Ev ödevi, Veli katılımı, Veli desteği, Matematik eğitimi

\footnotetext{
${ }^{1}$ Bu çalışmanın bir kısmı, 19-22 Haziran 2019 tarihlerinde Ankara'da düzenlenen VIth International Eurasian Educational Research Congress'de sözlü bildiri olarak sunulmuştur.
} 


\title{
Parental Involvement in Homework Discussions in Elementary Mathematics Education
}

\begin{abstract}
Homework is a natural connection path for encouraging parental involvement in learning. Also, parental involvement in math homework is one of the topics discussed in the international literature. In this study, firstly, parental involvement in homework was examined based on literature. In addition, theoretical framework for parental involvement in homework was mentioned. Later on, related to parental involvement in math homework, the studies in the world and Turkey were discussed. As a result of this review, the results were presented and supported by the researcher's suggestions. The aim of this study was to examine the parental involvement in math homework, which is frequently emphasized in mathematics education, based on literature and to provide a critical perspective in recent years. Thus, in the context of this study, in Turkey, it can shed light on parental involvement in math homework studies, which will be constructed in a field-specific structure in mathematics education. In the relevant literature, it seen that parental involvement in homework is a multi-dimensional structure. Most of the studies on parental involvement in homework are based on self-determination theory. According to this theory, there are two different types of parental involvement: Parental control and parental support. Studies report mixed results with regards to the effects of parental involvement in homework on children's educational outcomes. In Turkey, studies on parental involvement in math homework have been reported to be very limited. It is recommended to investigate the structure of the parental involvement in math homework, and to focus on which type of involvement will produce better results for the students.
\end{abstract}

Keywords: Math, Homework, Parental involvement, Parental support, Mathematics education 


\section{Giriş}

Ev ödevi (ödev), öğretmenler tarafından öğrencilere verilen, okul dışı zamanlarda tamamlanması gereken görevlerdir (Cooper, 2001). Ödevler öğrencilerin öğrenmelerini ve akademik becerilerini geliştiren önemli bir yöntem olarak görülür (Fan, Xu, Cai, He, ve Fan, 2017; Silinskas ve Kikas, 2019b; Trautwein, 2007). Ayrıca, iyi tasarlanmış ödevler öğrencilerin yaşam boyu öğrenme becerilerini de geliştirir (Boonk, Gijselaers, Ritzen, ve Brand-Gruwel, 2018; Fan vd., 2017). Öğrencinin ödeve yönelik çabası, ödev çıktılarının yordayıcısıdır (Trautwein ve Lüdtke, 2009). Matematik eğitimi alanında son yıllarda yapılan çalışma sonuçları ödeve yönelik çabanın aile gibi değişkenlerle ilişkili olduğuna dair kanıtlar sunmaktadır (Feng, Xie, Gong, Gao, ve Cao, 2019). Dolayısıyla, velinin ödeve katılımı, ödevin etkililiğine yönelik önemli bir faktördür (Dettmers, Yotyodying, ve Jonkmann, 2019). Bu bağlamda, mevcut çalışmada matematik ödevlerine veli katılımı ele alınarak, çeşitli boyutlarda irdelenmiştir.

Son yıllarda, politika düzenleyicilerin, uygulayıcıların ve eğitim araştırmacılarının veli katılımına yönelik ilgileri artmakta ve konuyla ilgili tartışmalar dikkat çekmektedir (Lerkkanen ve Pakarinen, 2019). Velinin ödeve katılımı da bu kapsamda tartışmaya açık bir durum ve araştırma alanı olarak kendini göstermektedir. Çünkü, ödev öğrenme sürecine veli katılımının geçişini sağlayan doğal bir bağlantı yoludur (Harris ve Goodall, 2008). Dolayısıyla, çocuğunun ödevine yardım etmek veli katılımının en tipik formudur (Silinskas ve Kikas, 2019b). Ancak, velinin ödeve kat1lımı ödev konusuna göre farklılaşabilir (Silinskas ve Kikas, 2019b; Xu, Du, Wu, Ripple, ve Cosgriff, 2018). Bu bağlamda, mevcut çalışmada velinin matematik ödevine katılımı alan yazın çerçevesinde incelenmiştir. Bunun temel nedeni, son yıllarda araştırmacıların özel bir konu alanı üzerine odaklanmanın önemine vurgu yapmalarıdır (Cunha, $\mathrm{Xu}$, Rosario, ve Núñez, 2018; Xu, Fan, Du, ve He, 2017).

Matematik ödevlerine veli katılımı uluslararası alan yazında gündemde olan konulardan biridir (Dettmers vd., 2019). Ancak, Türkiye'de velinin ödeve katılımını ele alan çalışmalar sınırlıdır (Coşkun-Keskin ve Özer; 2016; Duru ve Çöğmen, 2017; Kırmızıgül, 2018; Özcan ve Göğebakan-Yıldız, 2017; Turan-Özpolat, Karakoç ve Kara, 2017; Şen ve Gülcan, 2012; Yar-Yıldırım, 2018). Bu çalışmalarda, ilkokul (Ok ve Çalışkan, 2019; 
Şen ve Gülcan, 2012; Turanl,, 2009; Turan-Özpolat vd., 2017), ortaokul (Kırmızıgül, 2018; Yar-Yıldırım, 2018), hem ilkokul hem ortaokul (ilköğretim) seviyesinde (Coşkun-Keskin ve Özer, 2016; Duru ve Çöğmen, 2017; Özcan ve Göğebakan-Yıldız, 2017) öğrenim gören öğrenci velilerinin ödevlere yönelik görüşleri ve velilerin ödevlerdeki rolleri incelenmiştir. Çalışmalarda veliler öğrencilere ödev yapma sürecinde yardım ettiklerini belirtmişlerdir (Coşkun-Keskin ve Özer; 2016; Kırmızıgül, 2018; Şen ve Gülcan, 2012; Turan-Özpolat vd., 2017; Yar-Yıldırım, 2018). Ayrıca yapılan araştırmalarda, velilerin ödevlere yönelik bazı sorunlarla karşılaştığı vurgulanmıştır. Buna göre, veliler ilkokul öğrencilerinin ödevi yapmak istememelerini en büyük sorun olarak görmektedir (Duru ve Çöğmen, 2017). Ortaokul seviyesinde çocukları olan veliler ise çocuklarının ödev konusunu anlamamalarını sorun olarak ifade etmiştir (Kırmızıgül, 2018; Duru ve Çöğmen, 2017). Bunlara ek olarak, veliler öğretmenlerden ödev konusunda yeterince destek almadıklarını belirtmiştir (Özcan ve Göğebakan-Yıldız, 2017; Turanlı, 2009). Türkiye'de yapılan çalışmalarda görüşmeler (Coşkun-Keskin ve Özer, 2016; Ok ve Çalışkan, 2019; Turan-Özpolat vd., 2017; Yar-Yıldırım, 2018) veya anket formu (Duru ve Çöğmen, 2017; Kırmızıgül, 2018; Özcan ve Göğebakan-Yıldız, 2017; Şen ve Gülcan, 2012; Turanl, 2009) aracıllğıyla velilerin ödevlere yönelik görüşleri alınmıştır. Ancak, çalışmalarda teorik çerçeveler göz önüne alınarak velinin ödeve katılımının incelenmediği görülmektedir. Ayrıca, çalışmalarda özel bir konu alanı yerine (Matematik, fen bilgisi gibi) genel olarak ödevlerle ilgili veli görüşleri alınmıştır. Matematik ödevlerine yönelik veli görüşlerini ve katılımlarını inceleyen çalışmaların (Kırmızıgül, 2018; Özcan ve Göğebakan-Yıldız, 2017) sınırlılığı dikkat çekmektedir.

$\mathrm{Bu}$ çalışmanın amacı, ilköğretim matematik eğitiminde velinin ödeve katılımını alan yazın ışığında tartışarak, eleştirel bir bakış açısı sağlamaktır. Çalışmada, matematik konu alanı üzerine odaklanılmıştır, çünkü diğer konu alanlarıyla kıyaslandığında matematiği öğrenmek ve anlamak daha fazla çaba gerektirir (Marsh vd., 2016). Bu nedenle, öğrencilerin ödevlerinde en çok yardıma ihtiyaç duydukları konuların başında matematik gelmektedir (Silinskas ve Kikas, 2019a). Çalışmada, özellikle ilköğretim matematik eğitimi seviyesinin ele alınma sebeplerinden biri, yapılan meta-analiz çalışmalarının, velinin matematik ödevine katılımının özel- 
likle ilköğretim seviyesinde yoğunlaşttğını göstermesidir (Cooper, Robinson ve Patall, 2006; Fan vd., 2017). Ayrıca, ortaöğretim seviyesindeki öğrencilerin matematik ödevlerinde velilerden yardım alma düzeyinin azaldığı belirtilmiştir (Boonk vd., 2018; Xu ve Corno, 2003). Çünkü, ilerleyen matematik konularında veliler yeterli matematik bilgisine sahip olmayabilir (Knapp, Landers, Liang ve Jefferson, 2017). Tüm bunların yanında, ilköğretim seviyesindeki matematik eğitiminin daha üst düzeydeki matematik eğitimine temel oluşturacağı düşünülmektedir. Belirtilen nedenlerden dolayı, bu çalışma ilköğretim matematik eğitiminde alana özgü bir yapıda kurgulanacak olan velinin matematik ödevine katılımı çalışmalarına 1şık tutabilir. Çalışma içeriğinin, velinin matematik ödevine katılımıyla ilgili kapsamlı ve etkili çalışmalar yapılmasına katkıda bulunacağı düşünülmektedir. Belirtilen gerekçeler doğrultusunda aşağıdaki sorulara yanıt aranmiştır.

- Matematik ödevlerinin önemi nedir?

- Velinin ödeve katılımı nedir?

- Velinin ödeve katılımına yönelik teorik çerçeve nedir?

- Velinin matematik ödevine katılımına ilişkin çalışmalar ne tür sonuçlar ortaya koymaktadır?

\section{Yöntem}

\section{Model}

Mevcut çalışma, ilköğretim matematik eğitiminde velinin ödeve katıl1mını alan yazın ışığında tartışmayı amaçlayan kuramsal analitik bir çalışmadır. Kuramsal analitik araştırmalar, bilgi edinmek amacıyla bilgi aramaya odaklanır ve bilginin derlenmesini içerir (Neel, 1981). Dolayısıyla, derleme şeklinde tasarlanan bu çalışmada, velinin matematik ödevine katılımına ilişkin mevcut durum betimlenmiş, genel bir perspektif çizilerek eleştirel bir analiz gerçekleştirilmiştir. 


\section{Süreç}

Çalışmada nitel veri toplama yöntemlerinden biri olan doküman incelemesi kullanılmıştır. Dokümanlar bir araştırmacı için hazır bilgi kaynağıdır. Dokümanlarda bulunan veriler betimleyici bilgi sunabilir, tarihsel bir anlayış önerebilir, değişim ve gelişimin takip edilmesini sağlayabilir. Doküman analizinin en büyük avantajlarından birisi de veri kaynağının nesnel olmasıdır (Merriam, 2018). Dokümanlar belirlenirken amaçlı örnekleme yöntemlerinden ölçüt örnekleme kullanılmıştır. Patton (1990) ölçüt örnekleme için belirli kriterleri önceden sağlayan durumlar ifadesini kullanmıştır. Bu bağlamda, alan yazında yer alan çalışmaların seçiminde velinin ödeve katılımını konu edinmesi, matematik ödevlerini içermesi, ilköğretim seviyesini kapsaması ölçüt olarak belirlenmiştir. Belirlenen ölçütler çerçevesinde "ev ödevi, veli katılımı, matematik eğitimi, matematik" anahtar kelimeleriyle veri tabanlarında (Web of Science, ERIC, PsychINFO, ULAKBIM Sosyal Bilimler Veri Tabanı, Asos Index, Google Scholar) tarama yapılmıştır. Epstein'in (1987) veli katılımına yönelik temel oluşturan çalışması referans alınarak günümüze kadar yapılan çalışmalarda velinin matematik ödevine katılımının nasıl ele alındığı, önemsendiği irdelenmiş, eleştirel bir bakış açısıyla sunulmaya çalışılmıştır. Uluslararası alan yazında velinin ödeve katılımını içeren meta-analiz çalışmaları (Boonk vd., 2018; Fan vd., 2017; Patall, Cooper ve Robinson, 2008; Vasquez, Patall, Fong, Corrigan ve Pine, 2016) incelenerek matematik ödevlerini ele alan çalışmalar ve 2019 yılında yapılan çalışmalar tartışılmıştır. Ulaşılan ulusal ve uluslararası çalışmalar alt problemler kapsamında incelenerek, ortaya çıkan bileşenlerin ortak yönleri ve farklılıkları açıklanmıştır. Böylelikle, velinin matematik ödevine katılımıyla ilgili bilgi sunmayı amaçlayan bir çalışma ortaya konmaya çalışılmıştır.

\section{Bulgular}

\section{Matematik Ödevi}

Bu çalışmada özel bir konu alanı olarak matematik ödevlerinin seçilmesinin bazı nedenleri vardır. Öncelikle, son yıllarda ödev üzerine yapılan 
çalışmalarda alana özgü yaklaşımın benimsenmesi vurgulanmakta ve çalışmalar bu doğrultuda yürütülmektedir (Cunha vd., 2018; Jay, Rose, ve Simmons, 2018; Silinskas ve Kikas, 2019a, 2019b). Bu konuda, Patall vd. (2008), gerçekleştirdikleri meta-analiz çalışmasında velinin ödeve katıl1mının öğrenci çıktıları üzerindeki etkisinin konu içeriğine göre değiştiği sonucuna ulaşmıştır. Ayrıca, son yapılan çalışmalar, velinin matematik ödevlerine katılım seviyesini yükseltmenin oldukça zor olduğunu ortaya koymaktadır (Jay vd., 2018; Patall vd., 2008).

Matematik öğrenciler açısından endişe verici konulardan biri olmaya devam etmektedir (OECD, 2014; Şengül ve Dereli, 2013). Öğretmenlerin en çok ödev verdiği konulardan biri matematiktir (Sun, Du, ve $\mathrm{Xu}, 2018$; Xu, 2015, Xu vd., 2017). Öğrenciler ödev yapma zamanlarının büyük bölümünü matematik ödevlerine ayırmaktadır (Fernández-Alonso, SuárezÁlvarez ve Muñiz, 2016; Sun vd., 2018; Xu, 2015; Xu vd., 2018). Ayrica, öğrenciler fizik, biyoloji, tarih gibi derslerden ziyade matematik konularında velilerinin daha sık yardım ettiklerini bildirmektedir (Trautwein ve Lüdtke, 2009).

Velinin matematik ödevine katılımı uluslararası alan yazında gündemde olan araştırma konularından biridir. Çünkü, matematik ödevini yapmak hem öğrenci hem veli açısından zor bir görev olarak görülmektedir (Karbach, Gottschling, Spengler, Hegewald, ve Spinath, 2013; Xu vd., 2017). Ayrıca, matematik ödevleri, öğrencilerin plan yapma, zor görevlerde 1srarlı olma, motivasyon, öz-düzenleme yeteneklerini daha çok işe koşmalarını gerektirir (Sun vd., 2018; Yang ve Xu, 2018). Dolayısıyla, matematik konu alanının ödev kapsamında önemli bir araştırma alanı olduğu söylenebilir. Dünyada yaşanan gelişmeler hakkında bilgi olma açısından mevcut çalışmada velinin matematik ödevine katılımına yönelik bilgi sunmak yararlı görülmektedir.

\section{Velinin Ödeve Katılımı}

Eğitim araştırmalarında veli katılımı, akademik başarı üzerindeki etkilerinden dolayı ilgi çeken konulardan biridir (Boonk vd., 2018). Ancak, veli katılımı hakkında araştırmacıların uzlaştığı ortak bir tanım bulunmamaktadır. Bu konuda, Grolnick ve Slowiaczek (1994) veli katılımını "velinin kaynakları çocuğa adaması" (the dedication of resources by the parent to the 
child) olarak tanımlarken, LaRocque, Kleiman ve Darling (2011) veli kat1lımını, velinin çocuklarının eğitiminde yer alması olarak ifade etmektedir. Baker'a (2015) göre veli katılımı, velilerin çocuklarının akademik başarılarına katkı sağlamak amacıyla çocuklarının eğitim-öğretim sürecine dahil olmalarıdır. Veli katılımı araştırmacılar tarafından farklı şekillerde ifade edilse de, tanımlardaki ortak nokta velinin çocuğunun eğitim-öğretim faaliyetlerine destek olmasidır.

Bazı araştırmacılar ise, veli katılımının özel bir tanımını yapmak yerine veli katılım türleri üzerine odaklanmışlardır (Boonk vd., 2018; Epstein, 1987). Bu konuda Boonk vd. (2018) araştırmacıların veli katılımını farklı boyutlarda ele aldığını, bu farklılığın veli katılımıyla ilgili yığılmalı bilgi birikiminin oluşmasında zorluk yarattığını belirtmişlerdir. Araştırmacılar (Boonk vd., 2018; Epstein, 1987) veli katılımında farklı göstergeler kullanan çalışmalardaki veli katılım türünü iki ana kategoride gruplamışlardır: Ev tabanlı katılım (Home-based involvement) ve okul tabanlı katılım (Schoolbased involvement). Ev tabanlı veli katılımında, velinin evde eğitim ve öğrenmeyle ilgili destek sağlaması söz konusudur. Veli çocuğuyla okul konuları hakkında iletişim kurar, çocuğunun ilerlemesini izler, öğrenme etkinliklerinde yönlendirici olur ve ödevlerine yardım eder. Çocuğun akademik başarısına yönelik veli beklentileri de ev tabanlı veli katılımı kategorisinde değerlendirilebilir. Okul tabanlı veli katılımında, velinin öğretmenle iletişim kurması ve okulla ilgili faaliyetlere katılması gibi etkinlikler gerçekleşir. Öğrencinin akademik başarısı ve veli katılımı arasındaki ilişki göz önüne alındığında, ev tabanlı ve okul tabanlı veli katılımı boyutları arasındaki ayrım önemlidir.

Veli ödev katılımı ev tabanlı katılım türüne girmektedir (Dettmers vd., 2019; Gonida ve Cortina, 2014). Ev-tabanlı veli katılımının öğrenci başarısına nasıl katkıda bulunduğunun daha iyi açıklığa kavuşturulması için velinin ödev katılımı son zamanlarda araştırmacıların yoğun bir şekilde dikkatini çekmektedir (Boonk vd., 2018; Dettmers vd., 2019; Feng vd., 2019; Gonida ve Cortina, 2014; Moroni, Dumont, Trautwein, Niggli, ve Baeriswyl, 2015; Patall vd., 2008, Xu vd., 2017; 2018). Ödevler çoğunlukla velilerin çocuklarının öğrenim hayatlarına katılımlarını arttırmak amacıyla kullanılır (Jay vd., 2018). Ayrıca, velinin ödeve katılımı öğrenci başarısını yükseltmek için önemli bir strateji olarak görülmektedir (Dumont, Trautwein, Nagy, ve Nagengast, 2012; Pattal vd., 2008). Bu konuyla ilgili 
olarak, Cooper (2001) ödevin öğretimsel amaçlarının dışında veli-öğrenci, veli-okul iletişimini sağlamaya hizmet ettiğini belirtmektedir. Ödev yapma sürecinde veliler çocuklarına sıklıkla yardım eder (Moroni vd., 2015; Patall vd., 2008). Dolayısıyla, ödevin veliler ve çocukları üzerinde etkileri vardır. Bu nedenle ödev hem pedagojik hem sosyokültürel açıdan önemlidir (Williams ve Williams, 2019).

\section{Velinin Ödeve Katılımına Yönelik Teorik Çerçeve}

Velinin ödeve katılımını ele alan çalışmalarda çoğunlukla öz-belirleme kuramı (self-determination theory) temel alınır (Ryan ve Deci, 2000). Ryan ve Deci (2000) öz-belirleme kuramıla bireyin yeterlik (competence), ilişki (relatedness) ve özerklik (autonomy) şeklindeki temel psikolojik ihtiyaçlarını açıklamışlardır. Dolayısıyla, öz-belirleme kuramı motivasyon ve bireyin psikolojik ihtiyaçlarını açıklayan bir kuramdır. Öz-belirleme kuramına dayanan çalışmalarda velinin ödeve katılımı iki boyutta ele alınmıştır: Veli kontrolü (parental control) ve veli desteği (parental support) (Dumont vd., 2012; Moroni vd., 2015; Núñez vd., 2015, 2017; Pomerantz, Moorman, ve Litwack, 2007; Silinskas ve Kikas, 2019a, 2019b).

Kontrol edici davranışlar veli tarafından çocuğa, özel bir hedefe yönelik, baskı kurmayı içerir (örneğin, ödevini güzel yap). Veli öğrenciye yardımda bulunduğu süreç boyunca çocuğu yönlendirmede emirler ve direktifler kullanır (Pomerantz vd., 2007). Ödev durumlarında veli kontrolü, öğrencilerin verilen görevi tamamlamalarına yönelik öğrenci üzerine uygulanan baskı ve kontrol olarak tanımlanabilir (örneğin, öğrencinin verilen ödevi tamamlayıp tamamlamadığını kontrol etmek, öğrenci yardım istemeden ödevine karışmak, ödev yapılmazsa çocuğu cezalandırmak) (Dumont vd., 2012; Moroni vd., 2015; Núñez vd., 2015; 2017; Pomerantz vd., 2007; Silinskas ve Kikas, 2019b).

Veli desteği ise ödev yapma sürecinde çocuğa destek ve cesaretlendirme sağlamaktır (örneğin, çocukların ödev yaparken ihtiyaç duydukları desteğe duyarlılık, çocuk tarafından talep edildiğinde problem çözmeye yardım etme, çocuk yardım istemeden ödevine katılmama ama yardıma gerek duyduğunda yardım etme). Veli desteğinde, çocuğun performansı, çabası ve ilerlemesi övülür, veli çocuğa okul ve ödev performansını önemsediğini bildirir (Dumont vd., 2012; Moroni vd., 2015; Núñez vd., 2015; 
2017; Pomerantz vd., 2007; Rogers, Theule, Ryan, Adams, ve Keating, 2009; Silinskas ve Kikas, 2019b). Böylece, velinin ödev desteği çocuğun matematik ödevlerinde kendine daha fazla güvenmesini sağlar (Yenilmez, 2006).

Veli desteği genel olarak içeriğe yönelik destek (Content-oriented Support) ve özerkliğe yönelik destek (Autonomy-oriented Support) şeklinde iki alt boyutta ele alınmaktadır (Moroni vd., 2015; Xu vd., 2017, 2018). Velinin içeriğe yönelik desteği çocuğun ödevini yaparken ailesinin konu ile ilgili yardım etmesi ve anlamadığı noktalarda ailenin çocuğuna kavramsal bilgileri açıklamasıdır (Xu vd., 2017). Özerkliğe yönelik destek, çocuğun çevresini keşfetmesine izin verme, problem çözme sürecinde aktif rol almasını sağlama ve cesaretlendirme olarak ifade edilir (Pomerantz vd., 2007). Velinin çocuğuna sağladığı özerklik desteği, çocuğun seçimlerine/fikirlerine saygı duymayı, bağımsız seçimler yapması için fırsatlar sunmayı, kontrol edici bir dil kullanmaktan sakınmayı ve özerk bir aile ortamı sunmayı gerektirir (Moroni vd., 2015). Ödev bağlamında, özerkliğe yönelik destek problemleri velinin çözmesi anlamına gelmemekle birlikte çocuk talep ettiğinde destek olmayı, konuları tartışmayı, ipucu ve fikir vermeyi içerir. Özellikle, okul ortamında olumsuz deneyimler yaşamış öğrenciler özerkliğe yönelik destek sayesinde becerilerini geliştirip motivasyonlarını artırabilirler (Silinskas ve Kikas, 2019a). Xu vd. (2017) tarafından özerkliğe yönelik destekle içeriğe yönelik desteğin farklı iki yapı olarak ele alınıp alınamayacağı üzerine çalışmaların sürdürülmesi gerektiği belirtilmiştir.

\section{Velinin Matematik Ödevine Katılımına İlişkin Çalışmalar}

Veli katılımı ile ilgili yapılan tartışmalar uzun yıllardır devam etmektedir. Ancak, son zamanlarda veli katılımıyla ilgili çalışmaların ödeve katılım gibi özel bir alana yoğunlaştığı görülmektedir (Fernández-Alonso, Álvarez-Díaz, Woitschach, Suárez-Álvarez ve Cuesta, 2017). Ayrıca, velinin ödeve katılımına odaklanan çalışmalar matematik gibi özel bir konu alanı bağlamında yürütülmektedir (Cunha vd., 2018; Silinskas ve Kikas, 2019a, 2019b). Bu çalışmada, velinin matematik ödevine katılımını farklı boyutlarda ele alan çalışmalar üç başlıkta sunulmaktadır. 
Velinin matematik ödevine katılımı ile öğrencinin matematik performansı arasındaki ilişki

İlk grupta yer alan çalışmalarda velinin matematik ödevine katılımı ile öğrencinin matematik performansı arasındaki ilişki incelenmiştir. Çalışmalarda velinin matematik ödevine katılımının öğrencinin matematik performansı üzerindeki etkisiyle ilgili farklı sonuçlar ortaya konulmuştur. Olumlu sonuçlar ortaya koyan çalışmalarda, veli katılımı öğrencinin yüksek matematik performansının önemli bir yordayıcısı olarak belirlenmiştir (Castro vd., 2015; Moon ve Hofferth, 2016). Castro vd. (2015) meta-analiz çalışmalarında velinin ödev katılımının öğrencilerin matematik başarılarıyla anlamlı düzeyde ilişkili olduğunu, ancak etki büyüklüğünün çok küçük olduğunu saptamışlardır. Otani (2019) çalışmasında velinin matematik ödevine katılımının öğrenci başarısıyla pozitif ve anlamlı düzeyde ilişkili olduğunu ortaya koymuştur. Buna göre, öğrenci matematik ödevini yaparken velinin ödev hakkında öğrenciyle iletişim kurup, onu izlemesi matematik başarısı üzerinde etkilidir. Matematik ödevlerine yönelik veli görüşlerini inceleyen Özcan ve Göğebakan-Yıldız (2017) ve Kırmızıgül'ün (2018) çalışma sonuçlarına göre veliler ödevlerin matematik başarısını olumlu etkilediğini düşünmektedir. Ayrıca, veliler çocuklarına matematik ödevlerini yaparken destek olduklarını bildirmişlerdir.

Olumsuz sonuçlar ortaya koyan çalışmalarda ise, velinin matematik ödevine katılımıyla öğrencinin matematik başarısı arasındaki ilişkinin anlamlı ve negatif olduğu saptanmıştır (Cunha vd., 2018; Domina, 2005; Lee ve Bowen, 2006; Patall vd., 2008; Silinskas, Niemi, Lerkkanen, ve Nurmi, 2013). Patall vd. (2008) velinin ödeve katılımıyla matematik başarısı arasında negatif ilişki bulmuştur. Bu durum, veli katılımının farklı formlarının farklı sonuçlarıyla ilgili olabilir. Veli, matematik bilgi düzeyine göre ödevin içeriğine yönelik katılım sağlarsa, bu durumun öğrencinin matematik başarısı üzerine pozitif etkisi vardır. Ancak, veli öğrencinin ödevini tamamlamasını basit bir şekilde izlerse bu durumda öğrencinin matematik başarısı üzerinde negatif etkisi oluşur (Jay vd., 2018). Ayrıca, bazı çalışmalarda velinin matematik ödevine katılımı ile çocuğun matematik başarısı arasında anlamlı bir ilişkili bulunmamıştır (Pezdek, Berry ve Renno, 2002). Bu konuda, Pezdek vd. (2002) tarafından yapılan çalışma sonuçları 
velinin matematik ödevine yardım için harcadığı zaman ile çocuğun matematik performansının ilişkili olmadığını göstermiştir.

Velinin matematik ödevine katılımıyla ilgili çalışma sonuçlarında çelişkiler görülmektedir. Araştırmacılar, bu çelişkinin nedenini farklı ölçme araçlarının ve farklı veli katılımı tanımlarının kullanımı olarak görmektedir (Otani, 2019; Silinskas ve Kikas, 2019a). Velinin matematik ödevine katılımını farklı açılardan ele alan araştırma sonuçları farklılaşmaktadır (Örneğin, velinin matematik ödevine katılımını Otani (2019) izleme ve iletişim açısından değerlendirirken, Silinskas vd. (2013) izleme, Silinskas ve Kikas (2019a) ise destek ve kontrol olarak değerlendirmiştir). Belirtilen nedenlerden dolayı, araştırma sonuçlarını genelleştirerek yorumlamak zorlaşmaktadır (Boonk vd., 2018; Otani, 2019).

\section{Velinin matematik ödevine katılım türlerinin eğitimsel çıktılara etkisi}

İkinci grupta yer alan çalışmalarda velinin matematik ödevine katılım türlerinin eğitimsel çıktılar üzerine etkileri incelenmiştir. Yapılan çalışmalarda dikkat çekici bir unsur velilerin sosyo-ekonomik ve bilişsel durumlarına ilişkindir. Çalışmalarda veli seçimlerinde homojen yapı oluşturacak şekilde şehirsel ve kırsal kesimden örneklem seçildiği, velilerin anne veya baba olma durumları, eğitim seviyeleri betimsel olarak sunulmuş ancak veriler bu değişkenlere göre analiz edilmemiştir. Veriler ölçeklerdeki özbildirimlere dayalı olarak ilişkisel veya yapısal eşitlik modeliyle analiz edilmiştir. Veli seçiminde en önemli kriter olarak veliye çocuğunun matematik ödevine yardım edip etmediği sorulmuştur. Dolayısıyla, veli özelliklerinin matematik ödevine katılıma etkisi gelecekte araştırılması gereken konulardan biri olarak görülmektedir. Velinin matematik ödevine katılım türlerinin eğitimsel çıtılara etkisi genel bir perspektif sunularak öncelikle Tablo 1'de gruplanmış ve sonrasında açıklanmıştır.

Öncelikle, velinin ödeve katılım türlerinden biri olan veli kontrolüne ilişkin çalışma sonuçları irdelenmiştir. Buna göre, çalışmalarda öğrenciler tarafından algılanan veli ödev kontrolünün öğrencinin matematik başarısıyla negatif ilişkili olduğu bulunmuştur (Boonk vd., 2018; Domina, 2005; Dumont vd., 2012; Karbach vd., 2013; Levpušček ve Zupančič, 2009; Núñez vd., 2015; 2017; Silinskas ve Kikas, 2019b; Xu vd., 2018). 
Tablo 1. Velinin matematik ödevine katılım türlerinin eğitimsel çıktılara etkisine ilişkin sonuçlar

\begin{tabular}{|c|c|c|c|c|}
\hline \multirow{2}{*}{ 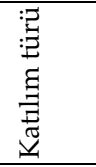 } & \multirow[t]{2}{*}{ İncelenen çıtı } & \multirow[t]{2}{*}{ Yazarlar } & \multicolumn{2}{|c|}{ Etki/İlişki } \\
\hline & & & $\begin{array}{l}\text { Olumlu } \\
\text { /Pozitif }\end{array}$ & $\begin{array}{l}\text { Olumsuz } \\
\text { /Negatif }\end{array}$ \\
\hline \multirow{15}{*}{$\begin{array}{l}\overrightarrow{0} \\
\stackrel{\Xi}{E} \\
\underline{0}\end{array}$} & Matematik & Boonk vd. (2018) & & $\mathrm{x}$ \\
\hline & başarısı & Domina (2005) & & \\
\hline & & Dumont vd. (2012) & & \\
\hline & & Gonida ve Cortina (2014) & & \\
\hline & & Karbach vd. (2013) & & \\
\hline & & Levpušček ve Zupančič ( 2009) & & \\
\hline & & Núñez vd. $(2015,2017)$ & & \\
\hline & & Silinskas ve Kikas (2019b) & & \\
\hline & & Xu vd. (2018) & & \\
\hline & $\begin{array}{l}\text { Sorumluluk ve } \\
\text { özerklik }\end{array}$ & $\begin{array}{l}\text { Fernández-Alonso, Suárez-Ál- } \\
\text { varez ve Muñiz (2015) }\end{array}$ & & $\mathrm{X}$ \\
\hline & Motivasyonel & Dumont vd. (2012) & & $\mathrm{x}$ \\
\hline & (öz-kavram, görev & Levpušček ve Zupanic (2009) & & \\
\hline & sürekliliği) & Rogers vd. (2009) & & \\
\hline & & Silinskas ve Kikas (2019b) & & \\
\hline & & Xu vd. (2018) & & \\
\hline \multirow{13}{*}{ 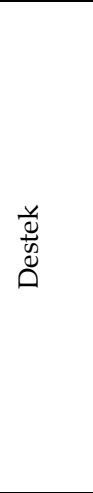 } & Matematik & Boonk vd. (2018) & $X$ & \\
\hline & başarısı & Dumont vd. (2012) & & \\
\hline & & Fernández-Alonso vd. (2016) & & \\
\hline & & Fernández-Alonso vd. (2017) & & \\
\hline & & Núñez vd. (2015) & & \\
\hline & & Rogers vd. (2009) & & \\
\hline & & Sheldon ve Epstein (2005) & & \\
\hline & & Silinskas vd. (2015) & & \\
\hline & & Trautwein ve Lüdtke (2009) & & \\
\hline & & Vasquez vd. (2016) & & \\
\hline & Motivasyonel (öz- & Núñez vd. (2015) & $\mathrm{X}$ & \\
\hline & kavram, görev & Patall vd. (2008) & & \\
\hline & sürekliliği) & Silinskas ve Kikas (2019b) & & \\
\hline \multirow{6}{*}{ 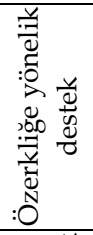 } & Matematik & Dumont vd. (2012) & $X$ & \\
\hline & başarısı & Feng vd. (2019) & & \\
\hline & & Fernández-Alonso vd. (2015) & & \\
\hline & & Gonida ve Cortina (2014) & & \\
\hline & & Martinez (2011) & & \\
\hline & & Xu vd. $(2017,2018)$ & & \\
\hline 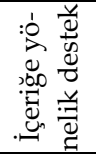 & $\begin{array}{l}\text { Motivasyonel } \\
\text { (öz-kavram, gö- } \\
\text { rev sürekliliği) }\end{array}$ & Martinez (2011) & $x$ & \\
\hline
\end{tabular}


Yapılan araştırmalarda, velinin bilişsel boyutundan ziyade öğrenci ve/veya velilerin öz-bildirim sonuçları ilişkisel açıdan değerlendirilip, kontrol edici veli katılımının matematik başarısıyla negatif ilişkisi ortaya konulmuştur. Genel olarak, algılanan veli ödev kontrolü ne kadar yüksekse öğrencinin matematik başarısının o kadar düşük olduğu söylenebilir.

Velinin kontrol edici ve müdahaleci şekilde matematik ödevlerine katılımının öğrencinin matematik başarısını yordamadığı bulunmuştur (Gonida ve Cortina, 2014). Ayrıca, bu tür veli katılımının öğrencinin sorumluluk ve özerkliğini azalttığı belirlenmiştir (Fernández-Alonso vd., 2015). Velinin ev ödevi sürecinde çocuğa baskı uygulaması aynı zaman çocuğun matematik öz-kavramı, öz-yeterliği ve amaç oryantasyonu ile negatif ilişkili bulunmuştur (Dumont vd., 2012; Levpušček ve Zupanic, 2009; Rogers vd., 2009; Silinskas ve Kikas, 2019b). Dumont vd. (2012) velinin matematik ödevini kontrol edici davranışlarının öğrencilerin matematik öz-kavram becerilerinin gelişimini engellediğini belirtmiştir. Velinin kontrol edici şekilde matematik ödevlerine katılımı öğrencilerin matematik dersine yönelik motivasyonların da olumsuz etkilemektedir (Boonk vd., 2018; Xu vd., 2018). Ayrıca, veli desteği öğrencilerin ödev davranışlarından biri olan görev sürekliliğini (task persistence) yükseltirken, veli kontrolü düşürmektedir (Silinskas ve Kikas, 2019b). Alan yazında dikkat çeken bir diğer durum, velinin ödeve katılımının öğrencinin eğitimsel çıktılarını yordaması yanında, öğrenci özelliklerinin de velinin ödeve katılım şeklini etkileyebildiğidir (Feng vd., 2019; Nunez vd., 2017; Silinskas ve Kikas, 2019a, 2019b; Silinskas, Kiuru, Aunola, Lerkkanen, ve Nurmi, 2015). Öğrencinin matematik performansı velinin ödeve katılımını en çok teşvik eden unsurdur (Nunez vd., 2017; Patall vd., 2008). Çalışmalar, öğrencinin matematik başarısının zayıf olmasının velinin daha çok kontrol edici davranmasına yol açtı̆̆ını ortaya koymuştur (Nunez vd., 2017; Patall vd., 2008; Silinskas vd., 2013, 2015, 2019b).

İkinci sırada, velinin ödeve katılım türlerinden biri olan veli desteğine yönelik çalışma sonuçları irdelenmiştir. Çalışmalarda, veli desteği yani daha dolaylı şekilde matematik ödevlerine katılımı öğrencinin matematik başarısını yükselten bir unsur olarak tespit edilmiştir (Fernández-Alonso vd., 2016, 2017; Núñez vd., 2015; Trautwein ve Lüdtke, 2009; Sheldon ve Epstein, 2005; Silinskas vd., 2015). Sheldon ve Epstein (2005) matematik ödevlerini yapma sürecinde etkili veli desteğinin öğrencinin matematik 
performansını geliştirdiğini belirtmişlerdir. Ayrıca, ilişkisel çalışmalarda veli desteğinin öğrencinin matematik başarısıyla pozitif ilişkili olduğu saptanmıştır (Boonk vd., 2018; Dumont vd., 2012; Núñez vd., 2015; Rogers vd., 2009; Vasquez vd., 2016).

Veli desteğinin bir alt boyutu olan özerkliğe yönelik destekle ilgili çalışma sonuçları da mevcuttur. Buna göre, özerkliğe yönelik destekle matematik başarısının pozitif ilişkili olduğu saptanmıştır (Boonk vd., 2018; Dumont vd., 2012; Feng vd., 2019; Fernández-Alonso vd., 2015; Gonida ve Cortina, 2014; Martinez, 2011; Xu vd., 2017, 2018). Fernández-Alonso vd. (2015) öğrencilerin matematik ödevlerini kendi kendilerine (özerk bir şekilde) tamamlamalarının matematik başarılarına pozitif katkı sağladığını belirtmiştir. Martinez (2011) ise, çalışmasında velinin öğrencinin ödevinde içeriğe yönelik destek sağlamasının ödevi tamamlama üzerinde pozitif etkileri olduğunu belirtmiştir. Ancak, geometri, cebir gibi alanlarda verilen ödevlere ilişkin velinin yardım edebilmesi için içerik bilgisi gereklidir. Yapılan çalışmaların, genel olarak veli katılımının kontrol ve destek yönüne yoğunlaştı̆̆ görülmektedir. Silinskas ve Kikas (2019b) velinin kontrol ve destek şeklinde matematik ödevine katılımının velinin bazı karakteristik özelliklerinden (bilişsel boyut, eğitim düzeyi gibi) etkilenebileceğini, bu nedenle bu karakteristik özelliklerin de göz önüne alınması gerektiğini vurgulamaktadır. Ayrıca, Silinskas ve Kikas (2019b) içeriğe ve özerkliğe yönelik destek türlerini ayırt etmeyi amaçlayan çalışmalar yapılması gerektiğine dikkat çekmektedir.

\section{Velinin matematik ödevine katılımında nicelik-nitelik sorunu}

Karmaşık bileşenler içeren veli katılımını değerlendirmek oldukça güçtür (Chen ve Zhu, 2017; Otani, 2019). Ayrıca, son yıllarda yapılan bazı çalışmalar velinin matematik ödevine katılımının öğrencide istenen çıktıları sağlamadığını göstermiş̧tir (Dettmers vd., 2019; Dumont vd., 2012; Karbach vd., 2013; Levpušček ve Zupančič, 2009; Núñez vd., 2015). Velinin matematik ödevine katılımının ölçülmesinde gruplar arası değişkenlerin (etnik köken, sosyo-ekonomik yapı vb.) veli katılımını nasıl etkilediğine yönelik bilgi yetersizdir (Aldous, 2006; Chen ve Zhu, 2017; Dettmers vd., 2019; Silinskas ve Kikas, 2019b). Ayrıca, velinin matematik ödevine katıl1- 
mında niteliğin (miktar değil) öğrenci çıktıları üzerinde çok daha etkili olduğu düşüncesi ağırlık kazanmaktadır. Dolayısıyla, araştırmacılar velinin matematik ödevine katılımının niceliğinden çok niteliğine odaklanılması gerektiği fikrinde buluşmuşlardır (Dettmers vd., 2019; Feng vd., 2019; Gonida ve Cortina, 2014; Moroni vd., 2015; Silinskas ve Kikas, 2019b). Daha önce bahsedilen çalışmalarda, veli ve öğrencilerin öz-bildirimleri aracıl1ğıla elde edilen veriler ilişkisel olarak incelenmiştir (Örneğin, Dettmers vd., 2019; Fernández-Alonso vd., 2015, 2016, 2017; Silinskas vd., 2013; Silinkas ve Kikas, 2019a, 2019b). Ancak, bu çalışmalarda velinin matematik bilgisi, sosyo-ekonomik durumu gibi değişkenlerin göz ardı edilmesi ve çalışmalarda tutarsız sonuçların ortaya çıkması, araştırmacıları farklı bir odağa yöneltmiştir: Veli katılımının niteliği. Bu doğrultuda, velinin matematik ödevlerine katılımının niteliğini incelemeye ve yükseltmeye dönük çalışmalar yapıldığ görülmüştür (Knapp vd., 2017; Tam ve Chan, 2009; Van Voorhis, 2011; Williams ve Williams, 2019). Bu konuda tasarlanan programlar, uygulamalar ve sonuçları açıklanmıştır.

Bir takım çalışmalarda, velilere matematik ödevlerine katılımla ilgili eğitimler verilerek sonuçları incelenmiştir (Tam ve Chan, 2009; Williams ve Williams, 2019). Tam ve Chan (2009) çalışmalarında velilere, çocuklarının ödevlerinde nasıl yardım edecekleriyle ilgili eğitim vermişlerdir. Bu eğitim sonrasında, velinin ödev yardımı, öğrencinin matematiğe yönelik pozitif tutumu ve matematik başarısı arasında anlamlı ilişki olduğu tespit edilmiştir. Williams ve Williams (2019) ise çalışmalarında velilere ödeve katılım konusunda eğitim verip, velinin özerkliğe yönelik katılımını geliştirmeyi amaçlamışlardır. Bu amaç doğrultusunda, günlük hayat problemleri içerikli matematik ödevleri tasarlamışlardır. Günlük hayat problemleri içerikli ödevlerin veli öğrenci etkileşimini ve velinin kendi matematiksel yeteneğine göre öğrenciye yardımcı olmasını geliştirdiği tespit edilmiştir.

Diğer çalışmalarda, eğitim programlarına sadece veliler değil, öğretmenlerin veya öğrencilerin de dahil edildiği görülmüştür (Knapp vd., 2017; Van Voorhis, 2011). Van Voorhis (2011) öğretmen ve velilere yönelik veli katılım programı tasarlayıp deneysel bir çalışma yürütmüşlerdir. Velileri ve öğretmenleri bu programa katılan öğrencilerin matematik başarılarının kontrol grubu öğrencilerine göre anlamlı derecede yüksek olduğu 
belirlenmiştir. Knapp vd. (2017) çalışmalarında, "Matematik ve Veli Ortaklığı Programı" (Math ve Parent Partners Program) kapsamında velilerin, öğrencilerin, öğretmenlerin eğitim almalarını sağlamışladır. Ayrıca, bu eğitimlerin sonuçlarını irdelemişlerdir. Program kapsamında velilerin matematiksel bilgilerini geliştirmeye yönelik uygulamalar gerçekleştirilmiştir. Program sonunda, öğretmenler için geçerli olan “Öğretim İçin Matematiksel Bilgi" (Mathematical knowledge for teaching) kavramına paralel olarak "Veli Katılımı İçin Matematiksel Bilgi" (Mathematical Knowledge for Parental Involvement) kavramı ortaya konulmuştur. Velinin matematiksel bilgisi geliştikçe öğrencilerin de matematik başarılarının geliştiği tespit edilmiştir. Eğitim verilen çalışmalardan farklı olarak Dettmers vd. (2019) boylamsal çalışmalarında velinin ödeve katılımının kalitesini yükselten faktörleri belirlemeyi amaçlamışlardır. Üç yıl süren çalışma sonunda, etkili okul-aile iletişimi (effective family-school communication) ve velinin ödeve katılımının niteliği arasında pozitif ilişki olduğu saptanmıştır. Ayrıca, velinin ödeve katılımı ve öğrencinin matematik başarısı arasında anlamlı ilişki olduğu tespit edilmiştir.

\section{Sonuç ve Öneriler}

Ödev, velinin çocuğunun öğrenme sürecine dahil olmasını sağlayan doğal bir köprü olarak görülmektedir (Harris ve Goodall, 2008; Silinskas ve Kikas, 2019b). Dolayısıyla, velinin ödeve katılımı eğitim çalışmalarında gündemde olan konulardan biridir. Ancak, velinin ödeve katılımının nicelik ve niteliği ödev konusuna göre değişebilir (Jay vd., 2018; Xu vd., 2018). Bu çıkarımdan hareketle, velinin ödeve katılımı çalışmaları son yıllarda belirli bir konu alanı bağlamında yürütülmektedir (Cunha vd., 2018, Silinskas vd., 2015, 2019a, 2019b; Otani, 2019). Üzerinde tartışmaların devam ettiği konu alanlarından biri de matematiktir. Çünkü, öğretmenler çoğunlukla matematik konularına yönelik ödev vermektedir. Dolayısıyla, öğrenciler de matematik ödevlerini yapmaya diğer derslerden daha fazla zaman ayırmaktadır (Sun vd., 2018; Xu, 2015; Xu vd., 2018). Bunun sonucunda da veliler en çok matematik ödevlerine katılmak durumundadır (Trautwein ve Lüdtke, 2009). Bu nedenlerden dolayı, çalışmada velinin ödeve katılımı matematik dersi bağlamında ele alınmıştır. 
Velinin ödeve katılımına ilişkin teorik çerçeve incelendiğinde, çoğunlukla "öz-belirleme kuramı"na (self-determination theory) dayanan çalışmalar yapıldığ 1 görülmüştür. Öz-belirleme kuramı çerçevesinde velinin ödeve katılımı iki alt boyutta ele alınmaktadır: Veli kontrolü (parental control) ve veli desteği (parental support) (Dumont vd., 2012; Moroni vd., 2015; Núñez vd., 2015, 2017; Pomerantz vd., 2007; Silinskas ve Kikas, 2019a, 2019b). Veli desteği ise kendi içinde içeriğe yönelik destek (Content-oriented Support) ve özerkliğe yönelik destek (Autonomy-oriented Support) olarak ikiye ayrılmıştır (Xu vd., 2017, 2018). Veli desteğinin, farklı alt yapılara ayrılıp ayrılamayacağı hala tartışılan konulardan biridir (Xu vd., 2017).

Velinin matematik ödevine katılımın farklı boyutlarda ele alan çalışmalar üç grupta incelenmiştir. Birinci grupta, velinin matematik ödevine katılımı ile öğrencinin matematik performansı arasındaki ilişkiyi belirlemeye yönelik çalı̧̧malar yer almaktadır. Bazı çalışmalarda, velinin ödeve katılımı öğrencinin yüksek matematik performansının önemli bir yordayıcısı olarak saptanmıştır (Castro vd., 2015; Moon ve Hofferth, 2016; Otani, 2019). Diğer bir grup çalışmada, velinin matematik ödevine katılımıyla öğrencinin matematik başarısı arasındaki ilişkinin negatif olduğu görülmüştür (Cunha vd., 2018; Domina, 2005; Lee ve Bowen, 2006; Patall vd., 2008; Silinskas vd., 2013). Nicel veriler sağlayan çalışma bulgularında çelişkili sonuçlar ortaya çıktığı görülmektedir.

İkinci grupta, velinin matematik ödevine katılım türlerinin eğitimsel çıktılara etkisini analiz eden çalışmalar vardır. Veli kontrolüne ilişkin çalışmalarda öğrenciler tarafından algılanan veli kontrolü ve matematik başarısı arasında negatif ilişki saptanmıştır (Boonk vd., 2018; Domina, 2005; Dumont vd., 2012; Karbach vd., 2013; Levpušček ve Zupančič, 2009; Núñez vd., 2015; 2017; Silinskas ve Kikas, 2019b; Xu vd., 2018). Ayrıca, çalışmalarda öğrencinin matematik başarısının zayıf olmasıyla velinin ödev sürecinde daha kontrol edici davrandığı ortaya konulmuştur (Nunez vd., 2017; Patall vd., 2008; Silinskas vd., 2013, 2015, 2019b).

Tam tersi bir sonuç olarak, veli desteği öğrencinin matematik başarısını yükselten bir öğe olarak belirlenmiştir (Fernández-Alonso vd., 2017; Núñez vd., 2015; Trautwein ve Lüdtke, 2009; Sheldon ve Epstein, 2005; Silinskas vd., 2015). Ayrıca, veli desteği ile matematik başarısı arasında pozitif ilişkili bulunmuştur (Boonk vd., 2018; Dumont vd., 2012; Núñez vd., 2015; Rogers vd., 2009; Sheldon ve Epstein, 2005; Vasquez vd., 2016). 
Benzer şekilde, veli desteğinin bir alt boyutu olan özerkliğe yönelik destekle matematik başarısının pozitif ilişkili olduğu saptanmıştır (Boonk vd., 2018; Dumont vd., 2012; Feng vd., 2019; Fernández-Alonso vd., 2015; Gonida ve Cortina, 2014; Martinez, 2011; Xu vd., 2017, 2018).

Üçüncü grupta ise velinin matematik ödevine katılımının niteliğini yükseltmeye dönük çalışmalar yapıldığı görülmüştür. Bu çalışmalarda matematik ve velinin ödeve katılımına yönelik programlar tasarlanmıştır. Çalışma sonuçlarına göre, velinin matematik ödevine katılımıyla ilgili eğitimler alması katılımın niteliğini geliştirmiştir (Knapp vd., 2017; Tam ve Chan, 2009; Van Voorhis, 2011; Williams ve Williams, 2019).

Ulusal ve uluslararası alanda yapılan çalışmalar kıyaslandığında, Türkiye'de, velinin ödeve katılımını inceleyen çalışmaların oldukça sınırlı olduğu görülmüştür (Coşkun-Keskin ve Özer; 2016; Duru ve Çöğmen, 2017; Özcan ve Göğebakan-Yıldız, 2017; Turan-Özpolat vd., 2017; Şen ve Gülcan, 2012; Yar-Yıldırım, 2018). Yapılan çalışmalarda genel olarak, velilerin ödevlere ilişkin görüşleri ve ödev sürecindeki rolleri incelenmiştir. Bu çalışmalarda matematik gibi özellikle bir derse odaklanılmamıştır. Velinin matematik eğitimine yaklaşımı genel olarak araştırılsa da (Yenilmez, Özer ve Yıldız, 2006), ödeve katılım özelinde çalışmalar yapılması gerektiği söylenebilir. Ulaşılan kaynaklar bağlamında, velinin matematik ödevine katılımı konusuna odaklanan çalışmaların oldukça az olduğu görülmektedir (Kırmızıgül, 2018; Özcan ve Göğebakan-Yıldız, 2017). Matematik ödevlerine yönelik veli katılımını inceleyen çalışma sayısının oldukça yetersiz olması dikkate değerdir.

Velinin matematik ödevine katılımında matematik ödevinin niteliği ve türleri öğrenci başarısını etkileyen değişkenlerden biridir (Rosario vd., 2015). Bu nedenle, ödev türlerinin (hazırlık, alıştırma, genişletme ödevleri gibi) veli katılımında nasıl farklılıklara yol açtığı araştırılabilir. Bazı araştırmacilar ise (Cunha vd., 2018; Silinskas ve Kikas, 2019; Xu vd., 2017) farklı kültürlerde veli katılımının incelenmesine yönelik çalışmalar yapılması gerektiğini vurgulamışlardır. Bu öneriye dayanarak, velinin matematik bilgisinin, eğitim seviyesinin ve sosyo-ekonomik yapısının matematik ödevine katılımını nasıl etkilediğine yönelik çalışmalar tasarlanması önerilmektedir. 
Çalışma kapsamında öncelikle, dünyada yoğun bir şekilde araştırılan velinin matematik ödevine katılımıyla ilgili nitel veya nicel çalışmalar yapılması önerilmektedir. İyi tasarlanmış boylamsal çalışmalarla, velinin matematik ödevine katılımının öğrenme çıktıları üzerine etkileri incelenebilir. Yapılacak çalışmalarda velinin matematik ödevine katılım yapısının araştırılması, hangi katılım türünün öğrenciler açısından daha iyi sonuçlar doğuracağı üzerine odaklanılması önerilmektedir. Ayrıca, velinin matematik ödevine katılımına ilişkin öğrenci algılarını inceleyen çalışmalar yapılabilir. Çalışmada ulaşılan alan yazına dayalı olarak, velinin matematik ödevine katılımı ve öğrencinin matematik başarısı arasındaki ilişkiyi açılayan çalışma sonuçlarının çelişkili olduğu görülmektedir (Castro vd., 2015; Cunha vd., 2018; Domina, 2005; Lee ve Bowen, 2006; Moon ve Hofferth, 2016). Bu çelişkili sonuçların nedenlerini derinlemesine incelemek ve daha ayrıntılı bilgi sahibi olmak için nitel çalışmalar yapılabilir. Velinin matematik ödevine katılımına yönelik yapılacak yeni çalışmalar; hem öğretmenlere, hem öğrencilere hem de velilere yönelik düzenlenecek olan eğitim programlarına alt yapı oluşturabilir.

Uluslararası alan yazında, son yıllarda velinin matematik ödevine katılımının niteliğini artırmaya dönük çalışmaların yapıldığı görülmektedir (Knapp vd., 2017; Williams ve Williams, 2019). Türkiye'de velilerin matematik ödevlerine nasıl etkin katılabilecekleriyle ilgili bilgilendirilmeleri önerilmektedir. "Velinin matematik ödevlerine katılımı nasıl daha etkili hale getirebilir?" sorusu bağlamında katılımının niteliğini artırmaya yönelik programlar tasarlanması önerilmektedir. Ayrıca, bu programların bilişsel ve duyuşsal çıktılara etkisi deneysel çalışmalarla incelenebilir. Öğretmenlerin velilerle olan iletişimleri göz önüne alındığında, öğretmen yetiştiren lisans programlarına matematik ödevlerinin önemi, türü, amacı, sıklığı, veli katılımı gibi içeriklerde derslerin eklenmesi yararlı görülmektedir. 


\title{
EXTENDED ABSTRACT
}

\section{Parental Involvement in Homework Discussions in Elementary Mathematics Education}

\author{
Fatma Erdoğan \\ Firat University
}

Homework is a task given by teachers to students, which must be completed outside school. Parental involvement in homework is an important factor for the effectiveness of homework. In recent years, the interest of policy-makers, practitioners and educational researchers towards parental involvement has been increasing and discussions about the issue have attracted attention. In this context, parental involvement in homework is a controversial situation and manifests itself as a field of research. Because homework has been reported to be a natural connection path to the learning process that enables the participation of parents. Therefore, helping the child's homework is the most typical form of parental involvement. In the present study, parental involvement in math homework was examined within the framework of literature. The main reason for this is that in recent years research on homework has emphasized the importance of focusing on a particular subject area. In addition, parental involvement in math homework is one of the topics discussed in the international literature. However, in Turkey, about math homework, overall, parents are consulted. The number of studies about parental involvement in math homework is very limited. In studies conducted in Turkey, considering theoretical frameworks, it is seen that parental involvement in math homework is not examined.

In this study, firstly, parental involvement in homework was examined based on literature. In addition, theoretical frameworks for parental involvement in homework were mentioned. Later on, related to parental involvement in math homework, the studies in the world and Turkey were discussed. As a result of this review, the results were presented and supported by the researcher's suggestions. The aim of this study was to exam- 
ine the parental involvement in math homework, which is frequently emphasized in mathematics education, based on literature and to provide a critical perspective in recent years. Thus, in the context of this study, in Turkey, it can shed light on parental involvement in math homework studies, which will be constructed in a field-specific structure in mathematics education. It is thought that the content of the study will contribute to the comprehensive and effective studies on parental involvement in homework-related.

Parental involvement in homework is a multi-dimensional structure. Most of the studies on parental involvement in homework are based on self-determination theory. According to this theory, there are two different types of parental involvement: Parental control and parental support. In the studies, the autonomous supportive assistance with homework was addressed in two sub-dimensions as content-oriented support and autonomy-oriented support. Studies on parental involvement in math homework can be grouped into three groups. In the first group of studies, the relationship between parental involvement in math homework and students' math performance was examined. Although in some stuides, parental involvement in math homework significantly predicted higher math performance, others indicated that parental involvement in math homework is negatively related to math achievement.

In the second group of studies, the effects of different parental involvement in math homework species on educational outcomes were examined. In some studies, parental homework control perceived by students was found to be negatively correlated with student's math achievement. On the other hand, parent support has been identified as an element that increases the math achievement of the student. In addition, parent support was found to be positively related to math achievement of the students. In the studies, different results related to the effects of parental involvement in math homework on students' mathematical performance were revealed. In addition, it has been stated in the studies that student characters also affect the shape of parental involvement in math homework. Information on how the parental involvement in math homework can be fully useful is not clear. Because the results of the relationship between parental involvement in math homework species and math achievement are contradictory. 
In the third group of studies, the issue of quality, not the quantity, has been taken into account on the topic parental involvement in math homework. In this direction, it has been observed that studies aimed at increasing the quality of parental involvement in math homework have been carried out.

In Turkey, studies on parental involvement in math homework have been reported to be very limited. In these studies, it was found that the opinions of parents about homework were not considered within the scope of a specific course. In the international literature, studies on parental involvement in math homework, quite a number of studies, while in Turkey, about this topic, relatively few studies have been made, it has been found is remarkable.

Based on the findings of the study, it is recommended that parents are informed about involvement in their children's math homework. In the undergraduate programs that train teachers, the importance of homework, type, purpose, frequency and parental involvement in homewrok can be added. In addition, experimental research can be designed to increase the quality of parental involvement in math homework. The researches can be done to address students' perceptions of parental involvement in math homework. With well-designed longitudinal studies, the educational outcomes of parental involvement in math homework can be examined. In the studies to be carried out, it is recommended to investigate the structure of the parental involvement in math homework, and to focus on which type of involvement will produce better results for the students. New studies related to the parental involvement in math homewrok, it can create infrastructure for both the teachers and students and the educational programs to be organized for parents.

\section{Kaynakça / References}

Aldous, J. (2006). Family, ethnicity, and immigrant youths' educational achievements. Journal of Family Issues, 27(12), 1633-1667.

Baker, C. E. (2015). Does parent involvement and neighborhood quality matter for African American Boys' kindergarten mathematics achievement? Early Educ. Dev., 26, 342-355. doi: 10.1080/10409289.2015. 968238. 
Boonk, L., Gijselaers, H. J. M., Ritzen, H. ve Brand-Gruwel, S. (2018). A review of the relationship between parental involvement indicators and academic achievement. Educ. Res. Rev., 24, 10-30. doi: 10.1016/j.edurev.2018.02.001.

Castro, M., Expósito-Casas, E., López-Martín, E., Lizasoain, L., NavarroAsencio, E. ve Gaviria, J. L. (2015). Parental involvement on student academic achievement: A meta-analysis. Educ. Res. Rev., 14, 33-46. doi: 10.1016/j.edurev.2015.01.002.

Chen, H. F. ve Zhu, J. (2017). Optimal items for assessing parental involvement across different groups during middle childhood. Journal of Child and Family Studies, 26(11), 2999-3012. doi:10.1007/s10826-0170809-2.

Cooper, H. (2001). Homework for all - in moderation. Educ. Leadership, 58, 34-38.

Cooper, H., Robinson, J. C. ve Patall, E. A. (2006). Does homework improve academic achievement? A synthesis of research, 1987-2003. Rev. Educ. Res., 76, 1-62. doi: 10.3102/00346543076001001.

Coşkun-Keskin, S. ve Özer, Ü. (2016). Velilere göre araştırmaya dayalı ödev anlayışı. Abant İzzet Baysal Üniversitesi Ĕ̆itim Fakültesi Dergisi, 16, (USBES Özel Sayı II), 1491-1512.

Cunha, J., Xu, J., Rosario, P. ve Núñez, J. C. (2018). Validity and reliability of the parental homework management scale. Psicothema, 30, 337-343. doi: 10.7334/psicothema2017.426.

Dettmers, S., Yotyodying, S. ve Jonkmann, K. (2019). Antecedents and outcomes of parental homework involvement: How do family-school partnerships affect parental homework involvement and student outcomes? Front. Psychol., 10 (1048). doi: 10.3389/fpsyg.2019.01048.

Domina, T. (2005). Leveling the home advantage: Assessing the effectiveness of parental involvement in elementary school. Sociology of Education, 78, 233-249. doi: 10.1177/003804070507800303.

Dumont, H., Trautwein, U., Lüdtke, O., Neumann, M., Niggli, A. ve Schnyder, I. (2012). Does parental homework involvement mediate the relationship between family background and educational outcomes? Contemporary Educational Psychology, 37, 55-69. doi:10.1016/j.cedpsych.2011. 09.004.

Duru, S. ve Çöğmen, S. (2017). İlkokul ve ortaokul öğrencileri ile velilerin ev ödevlerine ilişkin görüşleri. Ilköğretim Online, 16(1), 354-365. doi: 10.17051/io.2017.76577. 
Epstein, J. L. (1987). Toward a theory of family-school connections: Teacher practices and parent involvement. In K. Hurrelman, F. X. Kaufman, ve F. Losel (Eds.). Social intervention: Potential and constraints (pp. 121136). Berlin: de Gruyer.

Fan, H., Xu, J., Cai, Z., He, J. ve Fan, X. (2017). Homework and students' achievement in math and science: a 30-year meta-analysis, 1986-2015. Educ. Res. Rev., 20, 35-54. doi: 10.1016/j.edurev.2016.11.003.

Feng, X., Xie, K., Gong, S., Gao, L. ve Cao, Y. (2019). Effects of parental autonomy support and teacher support on middle school students' homework effort: Homework autonomous motivation as mediator. Front. Psychol., 10, 1-11. doi: 10.3389/fpsyg.2019.00612.

Fernández-Alonso, R., Álvarez-Díaz, M., Woitschach, P., Suárez-Álvarez, J. ve Cuesta, M. (2017). Parental involvement and academic performance: Less control and more communication. Psicothema, 29(4), 453-461. doi:10.7334/psicothema2017.181.

Fernández-Alonso, R., Suarez-Álvarez, J. ve Muniz, J. (2015). Adolescents' homework performance in mathematics and science: Personal factors and teaching practices. Journal of Educational Psychology, 107(4), 10757085. doi:10.1037/edu0000032.

Fernández-Alonso, R., Suárez-Álvarez, J. ve Muñiz, J. (2016). Homework and performance in mathematics: The role of the teacher, the family and the student's background. Revista de Psicodidáctica, 21, 5-23. doi:10.1387/RevPsicodidact.13939.

Gonida, E. N. ve Cortina, K. S. (2014). Parental involvement in homework: Relations with parent and student achievement-related motivational beliefs and achievement. British Journal of Educational Psychology, 84, 376-396. doi: 10.1111/bjep.12039.

Grolnick, W. S. ve Slowiaczek, M. L. (1994). Parents' involvement in children's schooling: A multidimensional conceptualization and motivational model. Child Development, 65, 237-252. doi: 10.1111/1467-8624. ep9406130692.

Harris, A. ve Goodall, J. (2008). Do parents know they matter? Engaging all parents in learning. Educational Research, 50(3), 277-289.

Jay, T., Rose, J. ve Simmons, B. (2018). Why is parental involvement in children's mathematics learning hard? Parental perspectives on their role supporting children's learning. SAGE Open, 8(2), 1-13. doi: 10.1177/ 2158244018775466. 
Karbach, J., Gottschling, J., Spengler, M., Hegewald, K. ve Spinath, F. M. (2013). Parental involvement and general cognitive ability as predictors of domain-specific academic achievement in early adolescence. Learning and Instruction, 23, 43-51. doi:10.1016/j.learninstruc. 2012.09.004.

Kırmızıgül, H. F. (2018). Ortaokul matematik dersinde verilen ev ödevlerine yönelik veli görüşlerinin bazı değişkenler açısından incelenmesi. (Yayımlanmamış yüksek lisans tezi). Frrat Üniversitesi, Elazı̆g.

Knapp, A., Landers, R., Liang, S. ve Jefferson, V. (2017). We all as a family graduate tonight: A case for mathematical knowledge for parental involvement. Education Studies in Mathematics, 95(1), 79-95.

LaRocque, M., Kleiman, I. ve Darling, S. M. (2011). Parental involvement: The missing link in school achievement. Preventing School Failure: Alternative Education for Children and Youth, 55, 115-122. doi: 10.1080/ 10459880903472876.

Lee, J. S. ve Bowen, N. K. (2006). Parent involvement, cultural capital, and the achievement gap among elementary school children. American Educational Research Journal, 43, 193-215. doi:10.3102/00028312043002193.

Lerkkanen, M. ve Pakarinen, E. (2019). The role of parental beliefs and practices in children's motivation in a changing World. Motivation in Education at a Time of Global Change: Theory, Research, and Implications for Practice Advances in Motivation and Achievement, 20, 151-167.

Levpušček, M. P. ve Zupančič, M. (2009). Math achievement in early adolescence: The role of parental involvement, teachers' behavior, and students' motivational beliefs about math. The Journal of Early Adolescence, 29, 541-570. doi: 10.1177/0272431608324189.

Marsh, H. W., Pekrun, R., Lichtenfeld, S., Guo, J., Arens, A. K. ve Murayama, K. (2016). Breaking the double-edged sword of effort/ trying hard: Developmental equilibrium and longitudinal relations among effort, achievement, and academic self-concept. Developmental Psychology, 52, 1273-1290.

Martinez, S. (2011). An examination of Latino students' homework routines. Journal Latinos Educ., 10, 354-368.

Merriam, S. B. (2018). Nitel araştırma desen ve uygulama için bir rehber. Selahattin Turan (Çeviri Editörü). Ankara: Nobel Akademik Yayıncllık. 
Moon, U. J. ve Hofferth, S. L. (2016). Parental involvement, child effort, and the development of immigrant boys' and girls' reading and mathematics skills: A latent difference score growth model. Learn. Individ. Differ. 47, 136-144. doi: 10.1016/j.lindif.2016.01.001.

Moroni, S., Dumont, H., Trautwein, U., Niggli, A. ve Baeriswyl, F. (2015). The need to distinguish between quantity and quality in research on parental involvement: The example of parental help with homework. Journal of Educational Research, 108, 417-431. doi:10.1080/00220671.2014. 901283.

Neel, R. G. (1981). Sosyal Davranışta Araştırma Yöntemleri (A. Can-Baysal, Çev.). İstanbul: Fatih Yayınevi Matbaası.

Núñez, J. C., Epstein, J. L., Suárez, N., Rosário, P., Vallejo, G. ve Valle, A. (2017). How do student prior achievement and homework behaviors relate to perceived parental involvement in homework? Frontiers in Psychology, 8, 1-13. doi:10.3389/fpsyg.2017.01217.

Núñez, J. C., Suárez, N., Rosário, P., Vallejo, G., Valle, A. ve Epstein, J. L. (2015). Relationships between perceived parental involvement in homework, student homework behaviors, and academic achievement: Differences among elementary, junior high, and high school students. Metacognition and Learning, 10, 375-406. doi:10. 1007/s11409-015-9135-5.

OECD (2014). PISA 2012 Results in focus: What 15-year-olds know and what they can do with what they know, PISA. Paris: OECD Publishing.

Ok, M. ve Çalışkan, M. (2019). Ev Ödevleri: Öğretmen, öğrenci ve veli görüşleri. OPUS-Uluslararası Toplum Araştırmaları Dergisi, 11(18), 594-620.

Otani, M. (2019). Parental involvement and academic achievement among elementary and middle school students. Asia Pacific Education Review, 20, 1-25. doi:10.1007/s12564-019-09614-z.

Özcan, B. N. ve Göğebakan-Yıldız, D. (2017). Velilerin çocuklarının matematik ödevlerine karşı görüş ve katılımlarının incelenmesi. TÜBAV Bilim, 10(4), 58-70.

Patall, E. A., Cooper, H. ve Robinson, J. C. (2008). Parent involvement in homework: A research synthesis. Rev. Educ. Res., 78, 1039-1101. doi: 10.3102/0034654308325185.

Patton, M. Q. (1990). Qualitative evaluation and research methods (2nd ed.). Newbury Park, CA: Sage. 
Pezdek, K., Berry, T. ve Renno, P. A. (2002). Children's mathematics achievement: The role of parents' perceptions and their involvement in homework. Journal of Educational Psychology, 94, 771-777. doi:10.1037/0022-0663.94.4.771.

Pomerantz, E. M., Moorman, E. A. ve Litwack, S. D. (2007). The how, whom and why of parents' involvement in children's academic lives: More is not always better. Review of Educational Research, 77, 373-410. doi: $10.3102 / 003465430305567$.

Rogers, M. A., Theule, J., Ryan, B. A., Adams, G. R. ve Keating, L. (2009). Parental involvement and children's school achievement: Evidence for mediating processes. Canadian Journal of School Psychology, 24, 34-57. doi: 10.1177/0829573508328445.

Rosario, P., Núnez, J. C., Vallejo, G., Cunha, J., Nunes, T., Mourao, R. ve Pinto, R. (2015). Does homework design matter? The role of homework's purpose in student mathematics achievement. Contemporary Educational Psychology, 43, 10-24.

Ryan, R. M. ve Deci, E. L. (2000). Self-determination theory and the facilitation of intrinsic motivation, social development, and well-being. American Psychologist, 55, 68-78. doi:10.1037/0003-066X.55.1.68.

Sheldon, S. B. ve Epstein, J. L. (2005). Involvement counts: Family and community partnerships and mathematics achievement. The Journal of Educational Research, 98, 196-206. doi:10.3200/JOER.98.4.196-207.

Silinskas, G. ve Kikas, E. (2019a). Math homework: Parental help and children's academic outcomes. Contemporary Educational Psychology, 59. doi: 10.1016/j.cedpsych.2019.101784.

Silinskas, G. ve Kikas, E. (2019b). Parental involvement in math homework: Links to children's performance and motivation. Scandinavian Journal of Educational Research, 63(1), 17-37. doi: 10.1080/00313831.2017. 1324901.

Silinskas, G., Kiuru, N., Aunola, K., Lerkkanen, M. K. ve Nurmi, J. E. (2015). The developmental dynamics of children's academic performance and mothers' homework-related affect and practices. Developmental Psychology, 51, 419-433. doi:10.1037/a0038908.

Silinskas, G., Niemi, P., Lerkkanen, M. K. ve Nurmi, J. E. (2013). Children's poor academic performance evokes parental homework assistanceBut does it help? International Journal of Behavioral Development, 37, 4456. doi:10.1177/ 0165025412456146. 
Sun, M., Du, J. ve Xu, J. (2018). Math homework purpose scale for preadolescents: A psychometric evaluation. Current Psychology, 1-9. doi:10.1007/s12144-018-9870-2.

Şen, H. Ş. ve Gülcan, M. G. (2012). İlköğretim 4. ve 5. sınıflarda verilen ev ödevleri konusunda veli görüşleri. Gazi Üniversitesi Endüstriyel Sanatlar Eğitim Fakültesi Dergisi, 29, 29-41.

Şengül, S. ve Dereli, M. (2013). Tam sayılar konusunun karikatürle öğretiminin 7. sınıf öğrencilerinin matematik tutumuna etkisi. Kuram ve Uygulamada Ĕ̆itim Bilimleri, 13(4), 2509-2534.

Tam, V. C. ve Chan, R. M. (2009). Parental involvement in primary children's homework in Hong Kong. School Community Journal, 19, 81-100.

Trautwein, U. (2007). The homework-achievement relation reconsidered: Differentiating homework time, homework frequency, and homework effort. Learning and Instruction, 17, 372-388. doi:10.1016/j.learninstruc.2007.02.009.

Trautwein, U. ve Lüdtke, O. (2009). Predicting homework motivation and homework effort in six school subjects: The role of person and family characteristics, classroom factors, and school track. Learning and Instruction, 19(3), 243-258. doi:10.1016/j.learninstruc.2008.05.001.

Turanl, A. S. (2009). Students' and paretns' perceptions about homework. Education and Science, 34(153), 61-73.

Turan-Özpolat, E., Karakoç, B. ve Kara, K. (2017). İlkokulda verilen ev ödevlerine ilişkin öğretmen ve veli görüşlerinin değerlendirilmesi. International Journal of Eurasia Social Sciences, 8(30), 1849-1890.

Van Voorhis, F. L. (2011). Adding families to the homework equation: A longitudinal study of mathematics achievement. Education and Urban Society, 43, 313-338. doi:10.1177/0013124510380236.

Vasquez, A. C., Patall, E. A., Fong, C. J., Corrigan, A. S. ve Pine, L. (2016). Parent autonomy support, academic achievement, and psychosocial functioning: A meta-analysis of research. Educ. Psychol. Rev. 28, 605644. doi: 10.1007/s10648-015-9329-z.

Williams, K. ve Williams, H. (2019). Mathematics problem-solving homework as a conduit for parental involvement in learning. Evaluation of a pilot study. Educational Review, 1-20. doi: 10.1080/00131911.2019. 1566210. 
$\mathrm{Xu}, \mathrm{J}$. (2015). Investigating factors that influence conventional distraction and tech-related distraction in math homework. Comput. Educ., 81, 304314. doi: 10.1016/j.compedu.2014.10.024.

Xu, J., Du, J., Wu, S., Ripple, H. ve Cosgriff, A. (2018). Reciprocal effects among parental homework support, effort, and achievement? An empirical investigation. Frontiers in Psychology, 9, 1-11. doi:10.3389/fpsyg.2018. 02334.

Xu, J., Fan, X., Du, J. ve He, M. (2017). A study of the validity and reliability of the parental homework support scale. Measurement 95, 93-98. doi:10.1016/j. measurement.2016.09.045.

$\mathrm{Xu}$, J. ve Corno, L. (2003). Family help and homework management reported by middle school students. Elemantary School Journal, 103(5), 503-518.

Yang, F., Xu, J., Tan, H. ve Liang, N. (2016). What keeps Chinese students motivated in doing math homework? An empirical investigation. Teachers College Record, 118(8), 1-26.

Yar-Yıldırım, V. (2018). Öğretmen, öğrenci ve velilerin ortaokul düzeyinde verilen günlük ödevler hakkındaki görüşleri. Milli Ĕ̆itim, 220, 201-224.

Yenilmez, K. (2006). Velilerin matematik eğitiminde çocuklarına sağladıkları katkı düzeyleri üzerine bir araştırma. Abant İzzet Baysal Üniversitesi Ĕ̆itim Fakültesi Dergisi, 6(1), 13-29.

Yenilmez, K., Özer, M. N. ve Yıldız, Z. (2006). Velilerin çocuklarının matematik eğitimine karşı yaklaşım ve katkılarının incelenmesi üzerine bir araştırma. Eskişehir Osmangazi Üniversitesi Sosyal Bilimler Dergisi, 7(1), 151-170.

\section{Kaynakça Bilgisi / Citation Information}

Erdoğan, F. (2020). İlköğretim matematik eğitiminde velinin ev ödevine katılımı tartışması. OPUS-Uluslararası Toplum Araştırmaları Dergisi, 15(22), 1481-1510. DOI: 10.26466/opus.658582 